\title{
Numerical Investigation of the Effect of Tower Dam and Rotor Misalignment on Performance and Loads of a Large Wind Turbine in the Atmospheric Boundary Layer
}

\author{
Gilberto Santo $^{1, *(\mathbb{D})}$, Mathijs Peeters ${ }^{2}$ (D), Wim Van Paepegem ${ }^{2}$ and Joris Degroote ${ }^{1}$ (D) \\ 1 Department of Flow, Heat and Combustion Mechanics, Ghent University, Sint-Pietersnieuwstraat 41, \\ 9000 Ghent, Belgium; joris.degroote@ugent.be \\ 2 Department of Materials, Textiles and Chemical Engineering, Ghent University, \\ Technologiepark-Zwijnaarde 907, 9052 Zwijnaarde, Belgium; mathijs.peeters@ugent.be (M.P.); \\ wim.vanpaepegem@ugent.be (W.V.P.) \\ * Correspondence: gilberto.santo@ugent.be
}

Received: 14 February 2019; Accepted: 25 March 2019; Published: 28 March 2019

\begin{abstract}
A modern horizontal axis wind turbine was simulated by means of computational fluid dynamics (CFD) simulations. The analyzed machine has a diameter of $100 \mathrm{~m}$ and is immersed in the atmospheric boundary layer (ABL). The velocity and turbulence stratification of the ABL is correctly preserved along the domain by the adoption of modified wall functions. An overset technique is employed to handle the rotation of the turbine rotor throughout the operation of the machine. The ABL induces periodically oscillating loads and generated torque on the rotor blades. Several configurations are analyzed. First, the results of a rotor-only simulation are compared to the ones obtained from the simulation of the full machine in order to evaluate the effect of the supporting structures on the produced torque and on the loads acting on the blades. Then, a tilt angle is introduced on the analyzed rotor and its effect on the oscillating loads of each blade is highlighted by comparing the results to the untilted configuration. Lastly, a yaw misalignment is also introduced and the results are compared to the unyawed configuration.
\end{abstract}

Keywords: wind turbine; atmospheric boundary layer; wind energy; tower dam; tilt; yaw; rotor misalignment

\section{Introduction}

Wind energy is a fast growing source of renewable energy. In the last decades, strong motivation for its further development has also been given by the goals established by both the European Union and the United States in order to increase the portion of electricity generated from renewable sources. As a result, research about wind energy has experienced a noticeable boost [1,2].

In terms of numerical modelling, a large number of complexities is involved when the aerodynamics of modern wind rotors are investigated. The growing dimensions of the rotors of horizontal axis wind turbines [3] are increasing the complexity even further. The high Reynolds number (up to $10^{8}$ ) and the atmospheric turbulence are challenging to simulate. The rotation of the moving parts and the presence of the supporting static structures of the machine (i.e., tower and nacelle) make the problem even harder to tackle and not representable by means of steady-state analysis. Moreover, wind turbines normally operate in the atmospheric boundary layer (ABL), namely a wind velocity increasing with height. This leads to the need to dynamically simulate the complete rotor, with the loads exerted on the blades oscillating in time. This interaction between the ABL and horizontal axis wind turbines 
was investigated by Calaf, Meneveau, and Meyers by means of large eddy simulations of wind farms. Their work highlighted a close relation between the wind shear and the power extraction $[4,5]$.

However, only a limited number of works take into account the effect of the ABL or the presence of supporting structures on the aerodynamics and power production of the single turbine, whereas traditional and widely used blade element momentum (BEM) theory [6] normally neglects these effects and limits the study to steady or quasi-steady state analysis. Furthermore, a tip-loss correction factor is needed for BEM theory to account for rotors with a finite number of blades instead of an actuator disk. A first correction was derived by Prandtl [7] and introduced by Glauert in the BEM technique [8]. More recently, Shen et al. [9] reviewed various tip loss corrections proposed over the years and highlighted how they fail to correctly predict the physical behavior in the proximity of the tip, also proposing a novel method to more accurately model the flow in this region. Moreover, the capability of a BEM code to account for the presence of the ABL or supporting structures is still very limited. This is reported only in the work of Dai et al. [10], who combined traditional BEM theory with a dynamic stall model, carrying out computations in which the ABL and the tower dam effect (i.e., the increase in pressure on the suction side of the blades due to their passage in front of the supporting tower) were accounted for.

Even though BEM provides a reasonable solution, the level of detail in the obtained results can certainly be improved. Sorensen and Kock [11] proposed an unsteady model for horizontal axis wind turbines, based on a general actuator disk concept and using a constant inlet wind speed. Xin Shen et al. [12] used an advanced lifting surface model to mimic the aerodynamics of the blade and also accounted for a sheared inlet wind velocity. Increasing the computational cost, Seydel and Aliseda [13] performed numerical simulations using a Reynolds-average Navier-Stokes (RANS) turbulence model (k- $\omega$ SST) in combination with a sliding interface approach to handle the relative rotation of the analyzed wind rotor; the ABL was approximated by a piece-wise linear wind velocity distribution. Similarly, Cai et al. [14] adopted a RANS model, coupled with a sliding interface technique, to simulate the dynamics of a wind turbine with supporting structures immersed in the $\mathrm{ABL}$, reproducing the wind velocity by a power law. All the works by Shen et al., by Seydel and Aliseda, and by Cai et al. reported sinusoidal loadings acting on the blades as a consequence of wind velocity stratification, highlighting the importance of the ABL in the simulations of modern wind turbines.

In the first part, this work will focus on the effect of the ABL and the presence of the supporting structures on the operation of a large (100 m diameter) commercial horizontal axis wind turbine, both in terms of performance and blade loading. A RANS turbulence model will be used, in combination with appropriate boundary conditions and modified wall functions, specifically adopted to ensure that the imposed ABL is preserved.

Additionally, a noticeable amount of research is currently being performed on the effect of rotor misalignment with respect to the incoming wind. However, most of the literature focuses on tilt and yaw misalignment as wake redirection techniques in wind farms, with the final goal of enhancing the global power production by letting every machine work outside the wakes of its neighbors. Fleming et al. [15] carried out a large quantity of large-eddy simulations (LES) with the objective of using the tilt angle and yaw misalignment (as well as turbine repositioning) of two turbines in a row to maximize their output power. Annoni et al. [16] performed a similar numerical investigation on a sole rotor tilting as a wake redirection technique and its effectiveness as a power gain strategy in wind farms. Noura et al. [17] used delayed detached eddy simulations (DDES) in combination with sliding interfaces to investigate the effect of a yaw misalignment on the wake of a small wind turbine, neglecting both the supporting structures and the ABL. Also, some experimental works on simplified small scale wind turbine models [18] or on full scale commercial turbines [19] have been carried out in order to maximize the power output.

Even though the current research focuses on rotor misalignment as a wake redirection technique in wind farms, every large horizontal axis wind turbine (HAWT) operates under tilted and yawed 
conditions. A small tilt is always imposed on the rotor and nacelle to provide the blades with more clearance from the tower, reduce the tower dam effect, and prevent collision due to large deflections. Additionally, LIDAR (light imaging, detection, and ranging) field measurements on large HAWTs have shown that, during normal operation, a yaw misalignment of 4 to 10 degrees is due to uncertainty in the wind direction measurement [20].

For these reasons, in the current work, the considered machine (always immersed in the ABL and in the presence of the supporting structures) is also simulated under tilted and tilted-yawed conditions, comparing the results with the untilted and unyawed configuration. A particular focus will be placed on investigating the aerodynamics of each blade, analyzing the effect of the imposed misalignments on their energy conversion performance as well as on the load acting on them. This represents the main novelty of the present work, compared to the works currently present in the literature and focusing on the effect of misalignments on the global power production of wind farms.

The details of the employed numerical model are given in Section 2, while the results of the performed simulations are discussed in Section 3. In that section, the results of the rotor-only and full-machine simulations are covered first, before analyzing the effect of tilt and yaw separately. Lastly, conclusions are drawn in Section 4.

\section{Methodology}

\subsection{Layout, Mesh, and Overset Approach}

The layout of the employed model is shown in Figure 1, together with the implemented boundary conditions and the details of the used meshes.

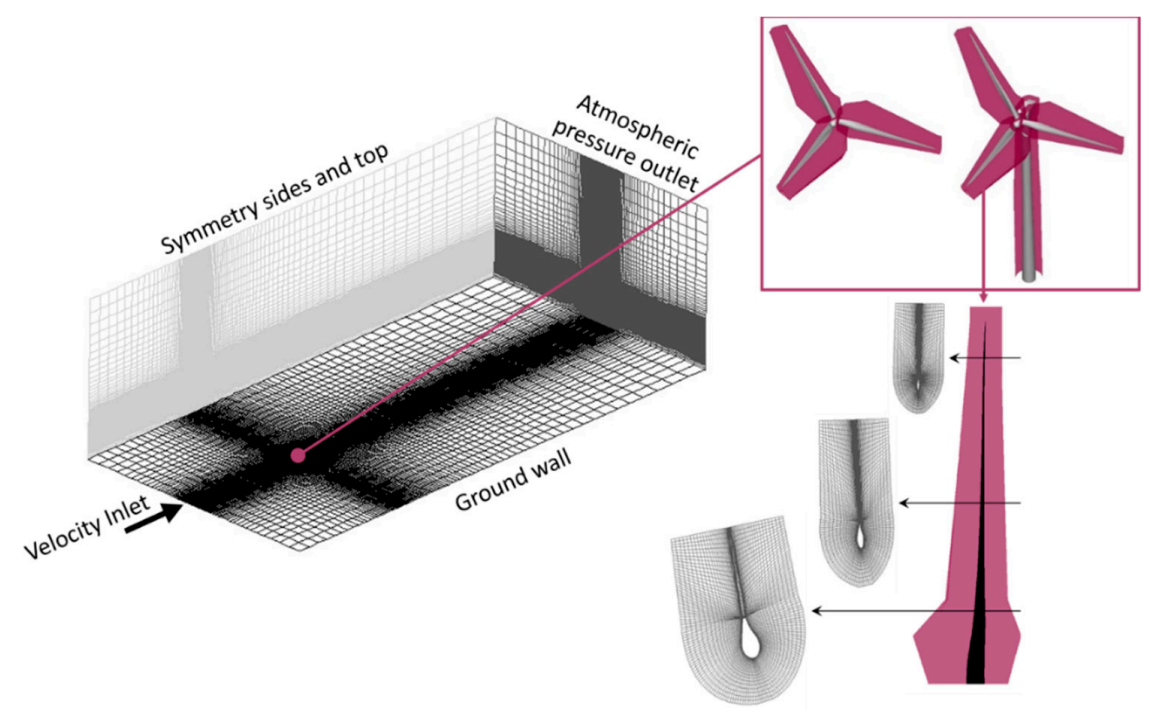

Figure 1. Layout of the performed simulations with details of the (left) background and (right) component meshes. Symmetry right side and top surfaces are omitted for clarity.

The geometry of the rotor and supporting structures (only in the full machine simulations) is modelled. The diameter of the rotor measures $100 \mathrm{~m}$ and the machine is placed as shown in Figure 1. The inlet and the pressure outlet (where the pressure is set to $1 \mathrm{~atm}$ ) are placed, respectively, 5 and 15 rotor diameters away from the rotor. The symmetry side and top surfaces (on which no orthogonal flow is allowed) are also positioned at a distance of 5 rotor diameters from the turbine location. These distances are chosen according to good practice guidelines for atmospheric flows [21] in order to avoid any artificial influence of the boundaries on the flow in the proximity of the turbine. Nevertheless, approximately half of these distances are adopted in similar computational fluid dynamics (CFD) works $[14,22]$ and were found to be sufficient to minimize any boundary influence [23]. 
A three-dimensional component mesh for the overset technique is generated around every object to be simulated, namely the three blades, the hub of the machine, and (for the full machine simulations) its supporting structures (tower and nacelle), as shown in Figure 1-right. The tower geometry is selected to be suitable for machines of this size and is extracted from [24], with a height of $100 \mathrm{~m}$. The nacelle is $12 \mathrm{~m}$ long and its section measures $5 \mathrm{~m} \times 5 \mathrm{~m}$. The mesh on each blade wall is designed to ensure a $y^{+}$in the log layer (between 30 and 300). The mesh size is then increased away from the wall in order to be comparable to the mesh size $(0.275 \mathrm{~m})$ of the structured background grid (Figure 1-left) at the boundary of each component mesh. Figure 1-right shows several sections of the fluid mesh around each blade, highlighting the C-grid adopted for its generation and the tapering and twisting of the blades, followed by the created mesh. The total number of cells in the computational domain is approximately 55 million, of which 1.9 million belong to each blade component mesh. In total, 38,500 faces are distributed on the surface of each blade. The mesh size is chosen according to previous studies performed by the authors [25]. All these meshes mutually overlay and are connected by means of an overset technique.

In order to illustrate how the mesh connectivity is established, Figure 2 shows the overlap of the generic background (left-hand side) and component (right-hand side) grids. On the background grid, the cells encompassed or crossed by wall surfaces of the component grid are deactivated. Then, on the outer boundary of the component grid, the flow quantities are obtained by interpolation from the background grid. In this region, the overlapping grids are created to have approximately the same cell size. The cells receiving solution by interpolation are referred to as "receptor cells" and marked in blue in Figure 2. The cells selected to provide solution for the receptor cells are addressed as "donor cells" and are marked in red in Figure 2. Note that the donor cells are a sub-group of the green cells ("solve cells"), where the governing equations are solved. The same mechanism is applied (in reversed direction) to the region around the walls of the component grid to provide boundary conditions to the background grid (blue region in Figure 2-left). Similar overset techniques have already been applied in aerodynamic models of wind turbines $[26,27]$.

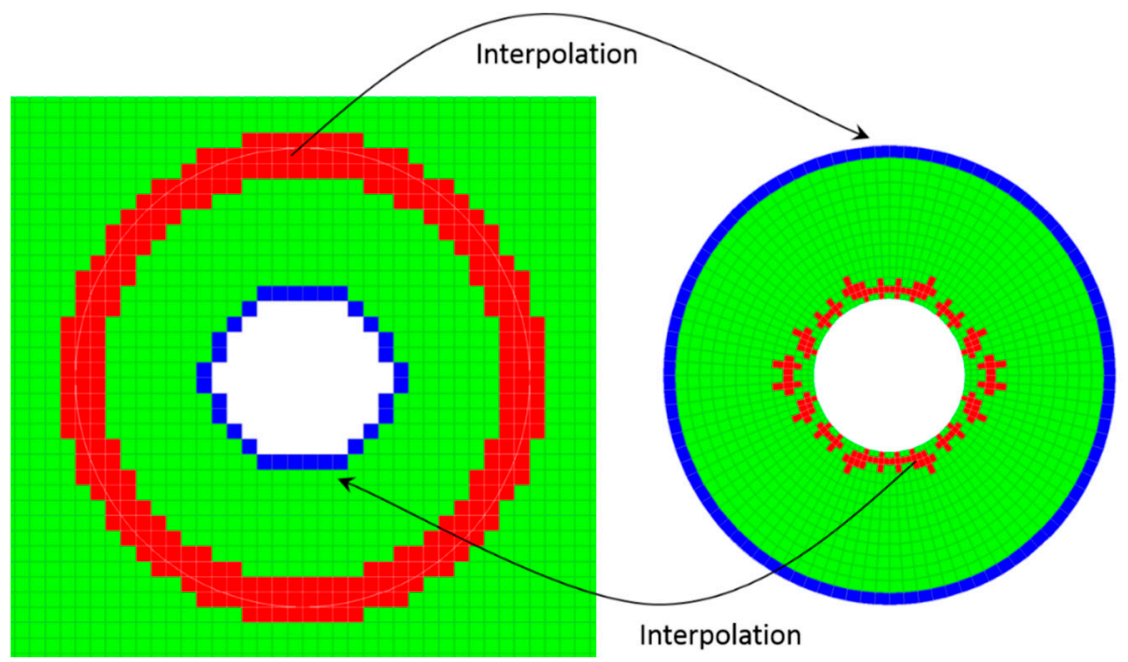

Figure 2. Mesh connectivity technique: (left) background grid and (right) component grid. Green corresponds to "solve cells", red to "donor cells", and blue to "receptor cells".

\subsection{Turbulence Modelling and Modified Wall Functions}

The chosen turbulence model is an unsteady RANS, specifically the k-epsilon model, where $k$ represents the turbulent kinetic energy and $\varepsilon$ is its dissipation rate. On top of the molecular viscosity, a turbulent viscosity is added and defined as $\mu_{t}=C_{\mu} \rho \frac{k^{2}}{\varepsilon}$ with $C_{\mu}$ equal to 0.09 and $\rho$ the density of air $\left(1.225 \mathrm{~kg} / \mathrm{m}^{3}\right)$ 
In order to mimic the ABL stratification under neutral conditions, the inlet conditions proposed by Richard and Hoxey [28] are adopted for the wind speed, $u$, and the turbulence quantities, with $\mathrm{z}$ the height, thus the distance from the ground wall is:

$$
\begin{gathered}
u(z)=\frac{u_{*}}{\mathrm{~K}} \ln \left(\frac{z+z_{0}}{z_{0}}\right) \\
k=\frac{u_{*}^{2}}{\sqrt{C_{\mu}}} \\
\varepsilon(z)=\frac{u_{*}^{3}}{\mathrm{~K}\left(z+z_{0}\right)}
\end{gathered}
$$

In these equations, $u_{*}$ is the ABL friction velocity, representing an index of the global wind intensity, while $z_{0}$ is the aerodynamic roughness length, providing a measure of the roughness of the ground wall. Lastly, $\mathrm{K}$ is the von Karman constant (0.4187). These profiles are obtained as analytical solutions of the transport equations of the k-epsilon model.

As observed by Blocken et al. [29] and Parente et al. [30], a novel formulation of the ground wall functions is necessary to preserve these inlet profiles throughout the numerical domain. For this reason, the aerodynamic roughness length is accounted for in the wall functions, following the novel formulation proposed and validated by Parente et al. [31], and obtaining a novel constant, E, and a novel non-dimensional wall distance, $y^{+}$:

$$
\begin{gathered}
z_{\text {nov }}^{+}=\frac{\left(z+z_{0}\right) u_{f} \rho}{\mu} \\
E_{n o v}=\frac{\mu}{\rho z_{0} u_{f}}
\end{gathered}
$$

where $u_{f}=C_{\mu}^{0.25} k^{0.5}$. This leads to a modified law of the wall for the non-dimensional velocity, $u^{+}$, given by:

$$
u^{+}=\frac{1}{K} \ln \left(z_{\text {nov }}^{+} E_{n o v}\right)
$$

In this work, the novel wall functions [31] presented above are addressed as "modified wall functions" and are adopted on the ground wall (Figure 1-left), in contrast with the standard ones adopted on the walls of the turbine.

Richard and Hoxey's ABL profiles are prescribed at the inlet of the domain (Figure 1), choosing $u_{*}=0.671 \mathrm{~m} / \mathrm{s}$ and $z_{0}=0.5 \mathrm{~m}$. At $100 \mathrm{~m}$ of height (namely the hub height), this produces a wind velocity of $8.5 \mathrm{~m} / \mathrm{s}$. The turbulent kinetic energy is set to $0.0151 \mathrm{~m}^{2} / \mathrm{s}^{2}$. The rotational speed of the rotor is set to $1.445 \mathrm{rad} / \mathrm{s}$, leading to a tip-speed ratio (TSR) of 8.5 , thus reproducing the nominal operating conditions as provided by the manufacturer. Given the low Mach numbers obtained in HAWTs, the flow is modelled as incompressible. The continuity and momentum equations are jointly solved in a pressure-based solver. Second order upwind discretization is applied for momentum equations and a first order implicit scheme is used for time discretization. The same settings are used for every simulation presented in this work. The entire setup is implemented in Fluent 18.1 (Ansys Inc., Canonsburg, PA, USA).

\subsection{Simulation Scenarios}

Several simulations are carried out and compared. First, a "rotor only" (RO) simulation is carried out, placing only the wind turbine rotor in the ABL flow with no misalignment with respect to the incoming wind. Then, the supporting structures are added, leading to the "full machine" (FM) simulation, as previously summarized by Figure 1 -right. The rotor and the nacelle of the machine are subsequently tilted by $5^{\circ}$, as shown in Figure 3, and as normally done in order to guarantee more 
blade-tower clearance during the operation of the machine. Lastly, a $5^{\circ}$ yaw misalignment is introduced by rotating the whole machine around an axis parallel to its tower, mimicking an incorrect orientation of the turbine. Both the tilt angle and the yaw misalignment are imposed by rotating the rotor around the appropriate axes crossing the center of the rotor, in order to guarantee the same position of this point (and thus exposing the rotor to the same ABL velocity gradient) in every simulation.

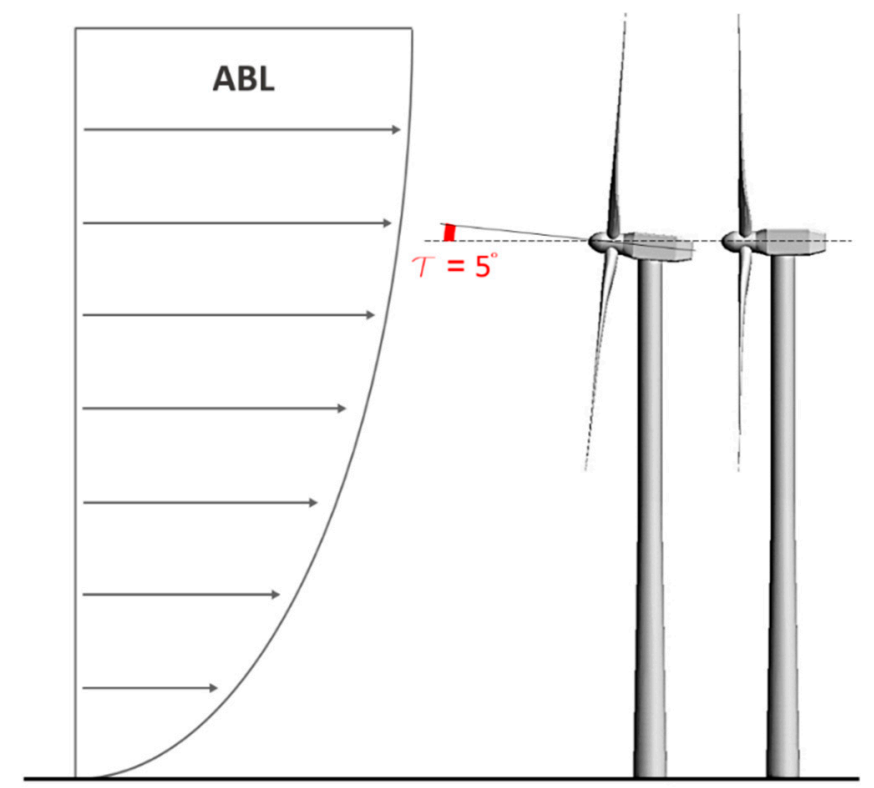

Figure 3. (left) Full machine tilted configuration and (right) untilted configuration with indication of the imposed atmospheric boundary layer (ABL).

Table 1 summarizes the performed simulations, showing the nomenclature to be adopted in the rest of this work and the features associated with each of them.

Table 1. Summary of the simulation scenarios analyzed.

\begin{tabular}{ccccc}
\hline Scenario Description & Scenario Name & Supporting Structures & Tilt & Yaw \\
\hline Rotor only & RO & None & $0^{\circ}$ & $0^{\circ}$ \\
Full machine & FM & Nacelle and tower & $0^{\circ}$ & $0^{\circ}$ \\
Full machine (with tilt) & FM + T & Nacelle and tower & $5^{\circ}$ & $0^{\circ}$ \\
Full machine (with tilt and yaw) & FM + TY & Nacelle and tower & $5^{\circ}$ & $5^{\circ}$ \\
\hline
\end{tabular}

Each revolution is divided into 240 time steps, so the time step size is $0.0181176 \mathrm{~s}$, and, starting from undisturbed ABL everywhere and wind turbine in stand-still, 6 revolutions are necessary to reach regime in time. Only the seventh revolution is analyzed; the average torque coefficient provided by the turbine during this revolution corresponds to 0.05243 (in the RO configuration), $5.8 \%$ off compared to the value provided by the manufacturer (0.0556), and used as a benchmark to validate the employed model.

All the simulations are performed on 10 computational nodes, interconnected by InfiniBand. Each node counts 28 cores of the type Xeon E5-2680v4. With these settings, roughly one day is necessary to perform a complete revolution in any of the presented simulation scenarios, summing up to a week to reach the time regime and obtain meaningful results.

\section{Results and Discussion}

In this section, the results of the performed simulations are analyzed and mutually compared. The notation illustrated in Figure 4 is used to define the azimuthal position of each blade. A cylindrical coordinate system will be used to define the radial, tangential, and axial (i.e., aligned with the axis 
of rotation of the machine) directions, according to Figure 4 and as normally done in the analysis of turbomachines.

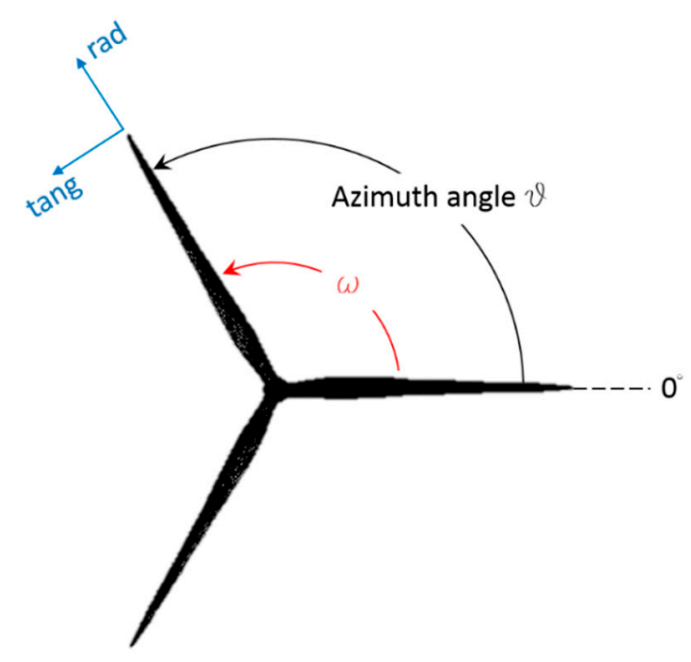

Figure 4. Notation adopted for the blade azimuth angle, $\vartheta$, and the components of the forces and velocities.

Moreover, as usually done in the wind energy field, the torque (T) exerted by the wind flow on the blades is made non-dimensional using the following formula:

$$
c_{T}=\frac{T}{\frac{1}{2} \rho v^{2} A R}
$$

where $\rho$ is the previously defined air density, $R$ the radius of the rotor, and $A$ is the frontal area computed as $A=\pi R^{2}$. The velocity, $v$, used in this formula is the undisturbed wind velocity at the hub height, namely $8.5 \mathrm{~m} / \mathrm{s}$. In order to allow a more immediate comparison, the frontal area, $A$, of the untilted and unyawed rotor will always be used when computing the torque coefficient.

In the following sections, analytical calculations of the flow angle on several blade sections will be performed and compared with the obtained CFD results. This is done by reasoning in the cylindrical coordinate system sketched in Figure 4. The streamwise velocity approaching a generic blade section, whose radial distance from the axis of rotation is $r$, can be computed from the ABL velocity profile as $v_{\text {stream }}=a \frac{u_{*}}{K} \ln \left(\frac{100 m+r \sin (\vartheta) \cos (\tau)+z_{0}}{z_{0}}\right)$, where $100 \mathrm{~m}$ corresponds to the hub height, $\vartheta$ is the azimuth angle defined in Figure 4, and $\tau$ is the tilt angle (illustrated in Figure 3 and equal to 0 in the RO and FM configurations). The factor $a$, is introduced to account for the reduction in the streamwise velocity due to the expansion of the streamtube [32] and is set to equal 0.75 based on the performed CFD simulations. In the RO and FM configurations, the streamwise velocity coincides with the axial velocity, whereas the tangential and radial wind velocity are equal to 0 . In the tilted and yawed configurations, the wind velocity components can be obtained by projecting the streamwise velocity expressed by the previous equation onto the tilted and yawed directions. These directions can be obtained by applying tilt and yaw rotation matrices to the directions valid for the untilted configurations. The axial and tangential wind velocity are then combined with the local blade speed $(\vec{u}$, purely tangential) and used to calculate the relative velocity vector, $\vec{w}$, impacting on the considered section, by means of the relation, $\vec{v}_{\text {wind }}=\vec{u}+\vec{w}$. Using axial and tangential components of $\vec{w}$, the flow angle is calculated.

We start with examining the total torque provided by the machine in all the considered configurations (Figure 5). 


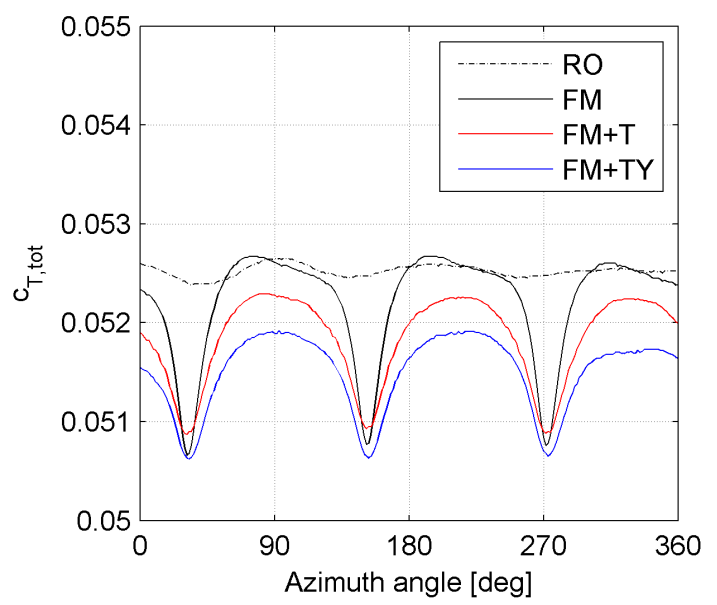

Figure 5. Total torque coefficient as a function of the azimuthal position of one blade. RO: Rotor only; FM: Full machine; FM + T: Full machine (with tilt); FM + TY: Full machine (with tilt and yaw).

In the RO configuration, the total torque coefficient is stable and exhibits only minor oscillations (deviation from average value smaller than $0.3 \%$ ). Differently, the FM configuration shows a sudden drop (about $3 \%$ of the average) in the provided torque every time one of the three blades passes in front of the tower (tower dam effect). This drop is mitigated by the tilt, but the average torque produced is slightly lower $(-0.7 \%)$. The same effect is further amplified by the yaw misalignment, which reduces the average torque by $0.66 \%$ compared to the $\mathrm{FM}+\mathrm{T}$ configuration. These reductions are to be expected since both the tilt and yaw misalignment have the effect of reducing the rotor frontal area with respect to the incoming wind. However, they are larger than the reduction in the frontal area, which corresponds to only $0.38 \%$ for both the tilted and tilted-yawed conditions.

We proceed now with examining a single blade, observing its performance and loading as a function of its azimuth angle. When doing so, the differences in the monitored loads when blades pass the same azimuth angle do not exceed $1 \%$, thus the regime is achieved and the behavior of each blade is representative of the other two.

First, the RO and FM simulations will be compared, in order to identify the influence of the ABL on the dynamics of each blade and show the effect of the presence of the supporting structures. Then, the tilt angle and yaw misalignment are addressed separately in order to clearly display their effects.

\subsection{Rotor Only and Full Machine Simulations}

Despite the stability of the total torque, the single blade contribution shows a sinusoidal oscillation in the $\mathrm{RO}$ configuration (Figure 6) as a direct consequence of the ABL.

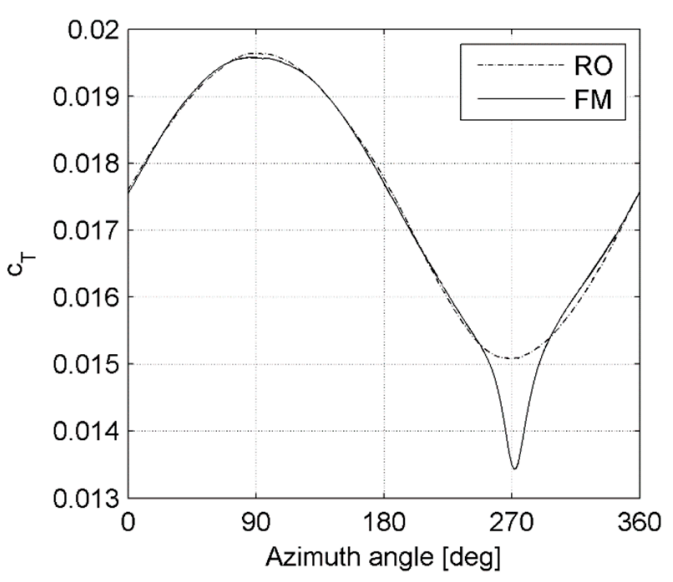

Figure 6. Torque coefficient contribution of each blade as a function of its azimuth angle: RO vs. FM. 
When the blade points upwards (azimuth angle between $0^{\circ}$ and $180^{\circ}$ ), it is exposed to a higher wind speed and thus the angle of attack over the entire blade is increased, leading to higher torque. The same reasoning reverses when the blade points downwards, i.e., for azimuth angle between $180^{\circ}$ and $360^{\circ}$. Qualitatively similar results were obtained in the literature $[13,14]$.

The two curves in Figure 6 almost perfectly overlap, except in the region around $270^{\circ}$, when the blade passes in front of the tower. At this moment, the tower represents an obstruction (tower dam effect) and increases the pressure on the suction side of the blade, reducing its performance. This also translates into a higher peak-to-peak amplitude of the oscillation of the torque. Figure 7 shows the average value (a) and the peak-to-peak amplitude of the oscillation (b) of the torque per meter of blade as a function of the span of the blade, obtained over the full revolution.

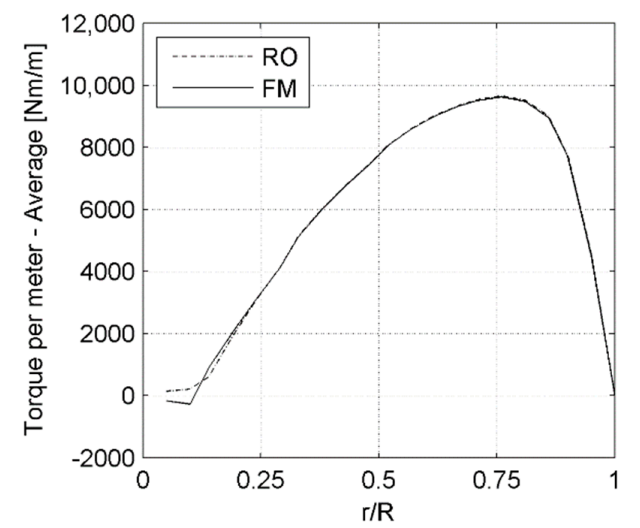

(a)

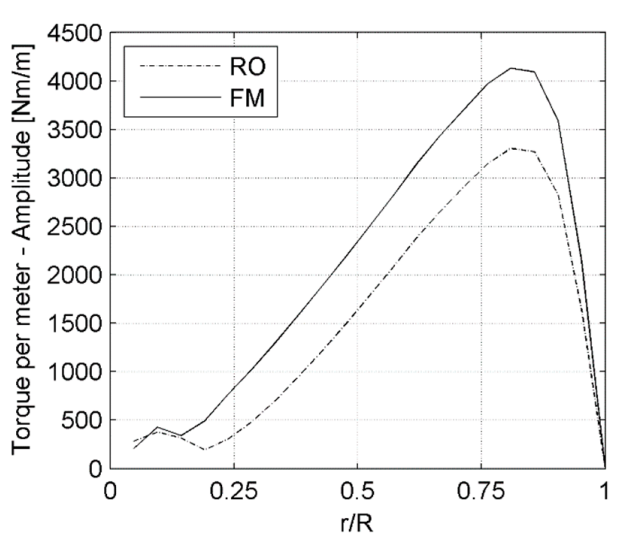

(b)

Figure 7. Torque per meter of blade as a function of the span: (a) average value and (b) peak-to-peak amplitude of the oscillation.

Except for the proximity of the root region, the reduction in the average torque value due to the presence of the supporting structures is lower than $0.6 \%$, thus no differences are visible in Figure $7 \mathrm{a}$. Differently, the peak-to-peak amplitude is consistently increased over the entire blade span (Figure 7b).

Reasoning similar to that identified for the torque can also be used for the axial force acting on the blade and a similar plot is shown in Figure 8 for the axial force. This is the most intense sollicitation acting on the blades and also the force responsible for the highest deflections [27,33,34]. Importantly, the consistent increase of its peak-to-peak amplitude of oscillation (Figure 8a) translates directly into less favorable conditions in terms of the fatigue life of the blade $[35,36]$.

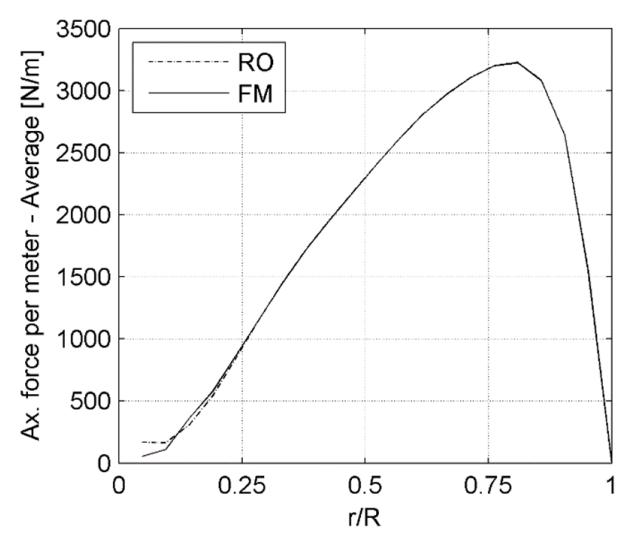

(a)

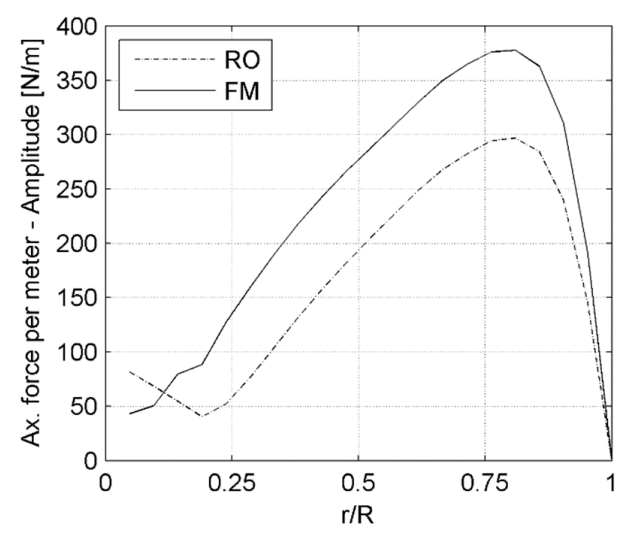

(b)

Figure 8. Axial force per meter of blade as a function of the span: (a) average value and (b) peak-to-peak amplitude of the oscillation. 


\subsection{Tilt Angle}

Figure 9 shows the torque contribution of the single blade in the FM and FM + T configurations.

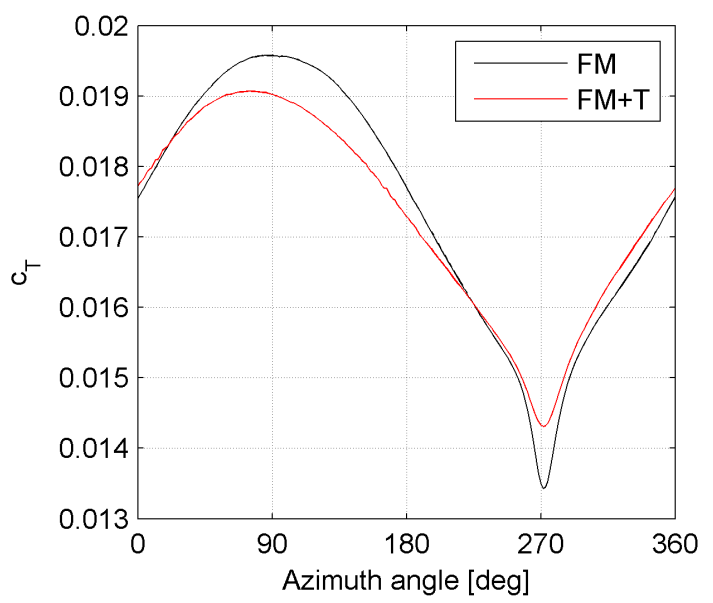

Figure 9. Torque coefficient contribution of each blade as a function of its azimuth angle: FM vs. $\mathrm{FM}+\mathrm{T}$.

The torque in the tilted configuration exhibits both a shift in phase (the positive peak is reached earlier with respect to the untilted configuration) and a decrease in the amplitude of its oscillation. The difference around $270^{\circ}$ can be attributed to the higher tower clearance, but the same does not apply to the difference around $90^{\circ}$. The shift in phase and the decrease in amplitude are independent of each other and come, respectively, from the inboard and outboard sections of the blade as shown in Figure 10. This will now be demonstrated.

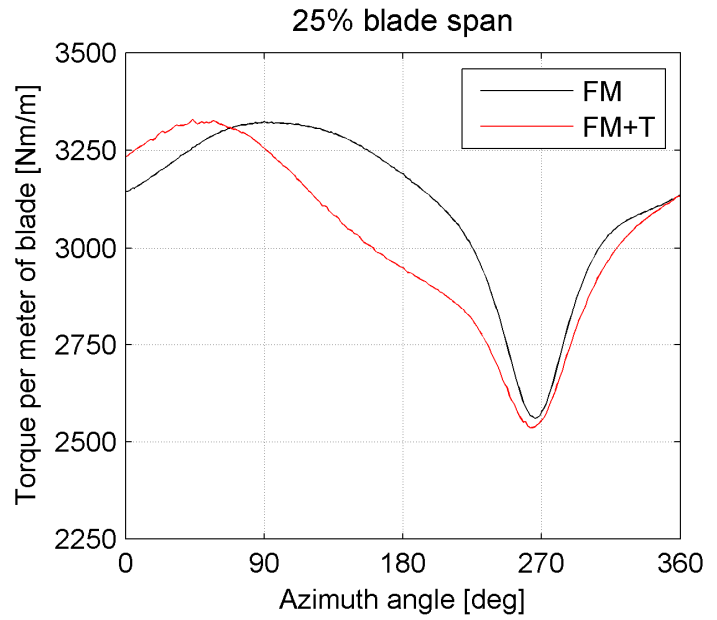

(a)

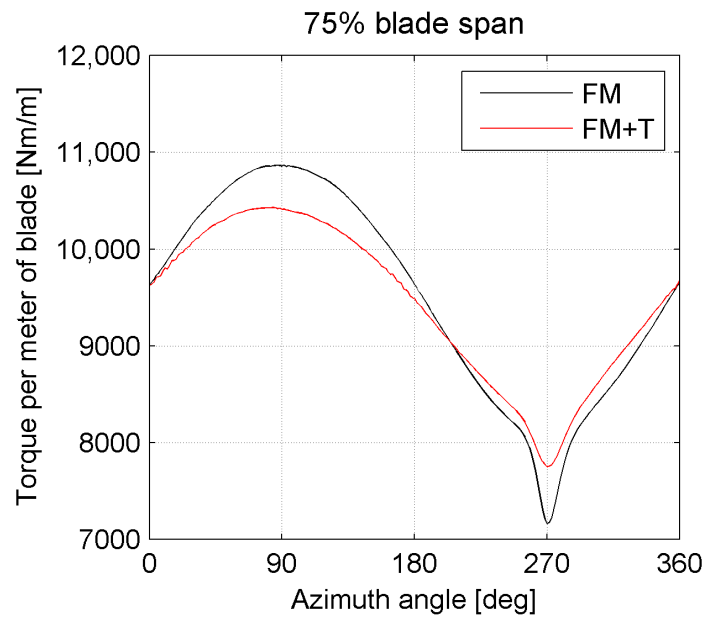

(b)

Figure 10. Torque (per meter of blade) contribution at two different spanwise locations: (a) 25\% and (b) $75 \%$ of the total span. Comparison between FM and FM + T configurations.

Focusing on the phase shift, Figure 11 shows the torque provided by different low span sections of the blade, normalized by the respective average value, for the FM + T simulation. 


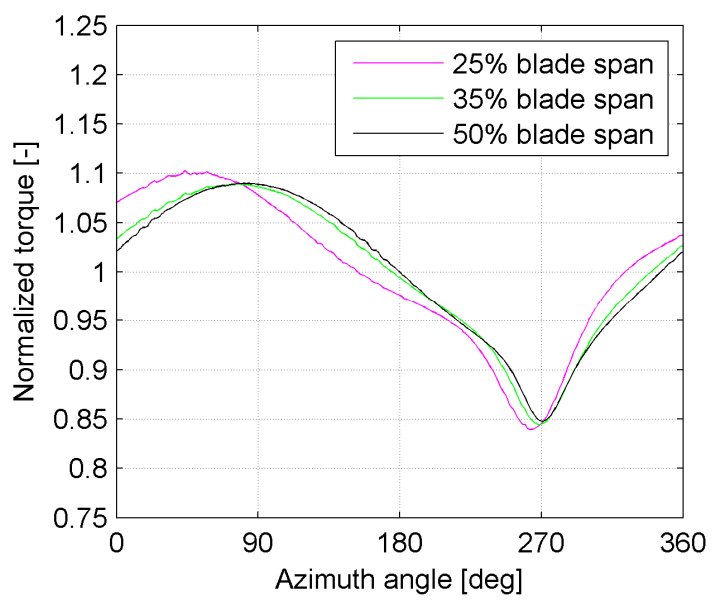

Figure 11. Normalized torque contribution at different span locations of the blade in $F M+T$ configuration.

It can be observed that, moving up along the span of the blade, the phase shift gradually disappears and, at $50 \%$ of the span, it is no longer observed. This shift can be related to the change in the local angle of attack induced by the tilt angle. Because of this angle, tangential and radial components originate from the wind velocity. The velocity triangles are consequently changed; this translates directly into a different distribution of the angle of attack, which is much more important in the inboard part of the blade, where the blade speed and the wind speed are comparable in magnitude. On the contrary, in the outboard section of the blade, the changes in the wind speed are small compared to the much higher blade speed. The flow angle can be computed as a function of the azimuthal position of the blade at the two examined spanwise locations (Figure 12).

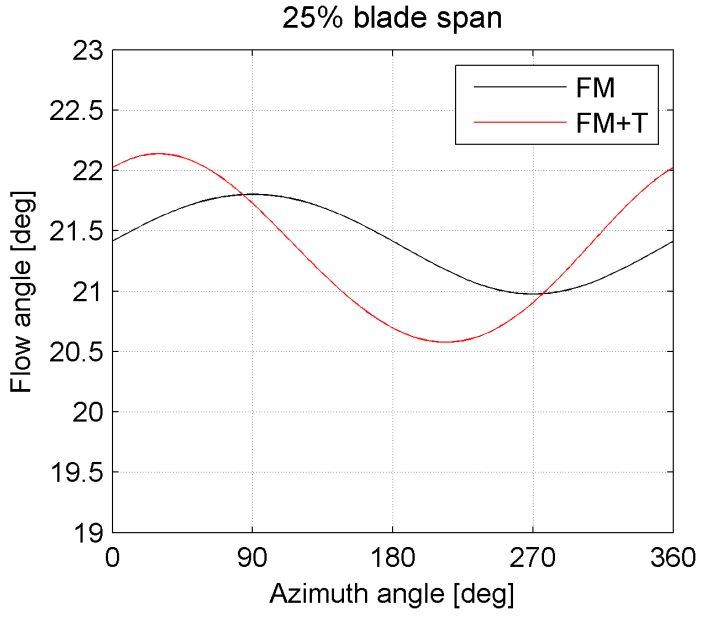

(a)

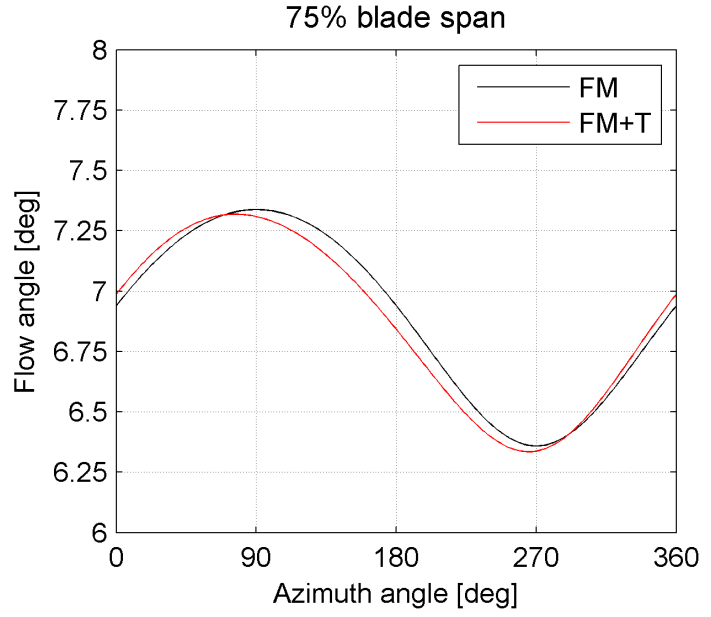

(b)

Figure 12. Computed flow angles at two different spanwise locations: (a) $25 \%$ and (b) $75 \%$ of the total span. Comparison between FM and FM + T configurations.

By comparing Figure 12 with Figures 10 and 11, synchronized peaks (i.e., arising around approximately the same azimuthal position) occurring in the torque and flow angle are observed for the inboard location, while only a minor phase shift is reported in the torque or flow angle at the outboard location. This confirms that the change in the flow angle is the cause for the phase shift close to the hub.

The reduction in amplitude occurring in the torque oscillation of the outboard spanwise location is not observed in the flow angle around the same position. This reduction in torque amplitude is attributed to the radial flow generated by the radial component of the wind velocity impacting on the 
pressure side of the blades. The radial flow is more intense on the outboard section, since it is directly linked to the recirculation over the blade tip, while it does not sensibly affect the inboard section of the blade (Figure 13).

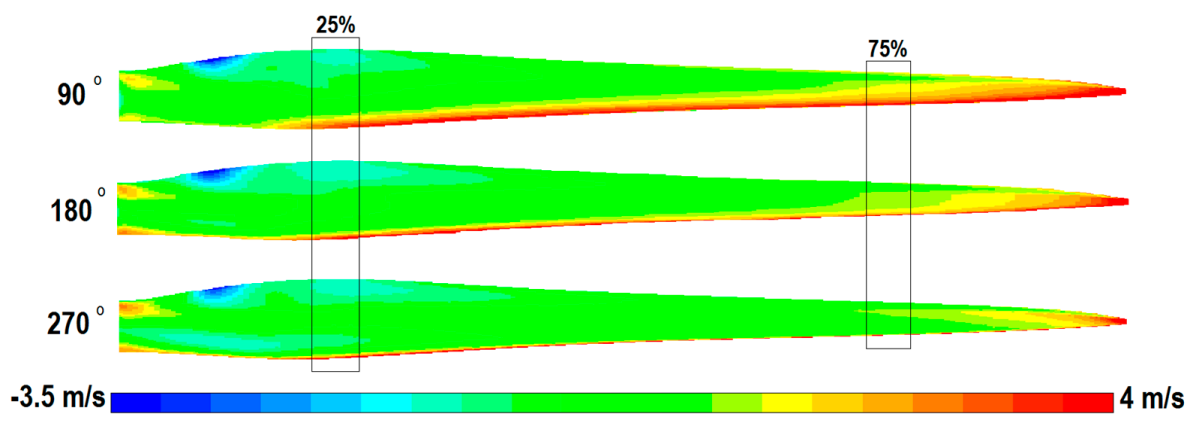

(a)

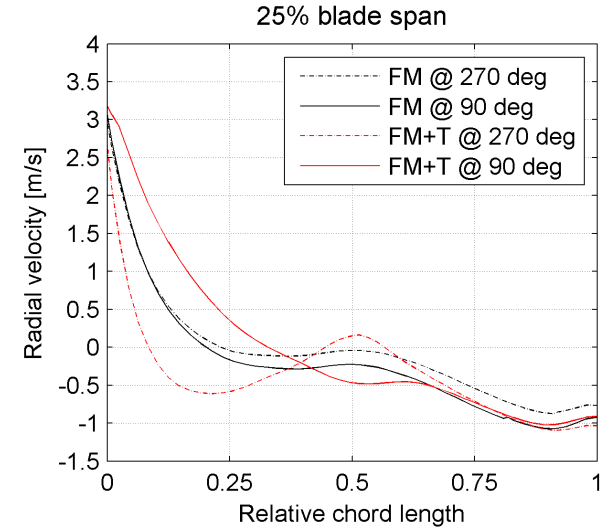

(b)

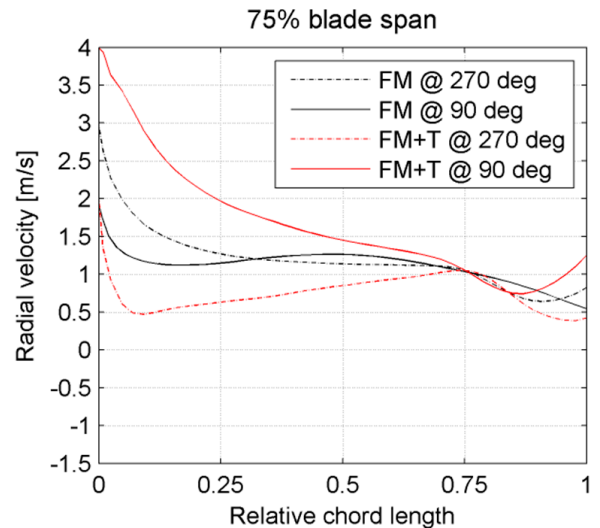

(c)

Figure 13. (a) Contours of the radial velocity in the first computational cell attached to the blade wall over the pressure side of the blade at a $90^{\circ}, 180^{\circ}$, and $270^{\circ}$ azimuth angle in the $\mathrm{FM}+\mathrm{T}$ configuration (see Figure 4 for the sign convention) and a comparison of the same velocity at (b) $25 \%$ and (c) $75 \%$ of the blade in the FM $+\mathrm{T}$ and FM configuration.

A centrifugal flow on the pressure side of the blade will inevitably favor the tip leakage flow (addressed also as "tip loss") by increasing the amount of fluid circulating over the tip of the blade and towards its suction side, decreasing the efficiency of the energy capture [8,9,32]. Figure 14 shows the analytically computed radial wind velocity impacting on the location at $75 \%$ of the total span.

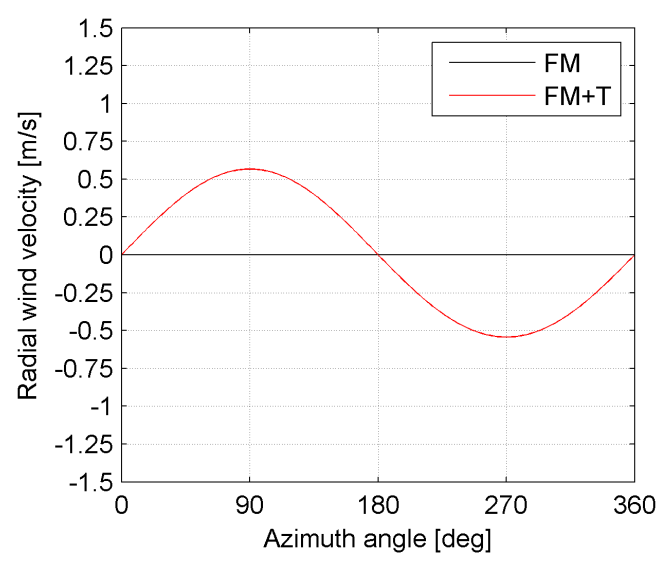

Figure 14. Computed impacting radial wind velocity at $75 \%$ of the blade span (see Figure 4 for the sign convention). 
For an azimuth angle of $270^{\circ}$, the radial velocity (Figure 13c) in the first cell attached to the blade wall at $75 \%$ of the span, averaged over the entire chord length on the pressure side, is $1.23 \mathrm{~m} / \mathrm{s}$ for the untilted configuration and $0.77 \mathrm{~m} / \mathrm{s}$ for the tilted configuration. The difference between these numbers $(0.46 \mathrm{~m} / \mathrm{s})$ is comparable to the analytically computed difference at $270^{\circ}$ and equal to $0.54 \mathrm{~m} / \mathrm{s}$ (Figure 14). It can be seen that when the impacting radial velocity is positive (i.e., centrifugal), a loss in torque is observed in Figure 10a. On the contrary, when the impacting radial velocity is negative (i.e., centripetal), a beneficial effect (due to a reduction in the tip loss) is seen, as shown in Figure 10a. Figure 15 shows how the reduction in amplitude of the torque oscillation increases towards the tip, where the tip loss has a higher impact on the blade performance $[8,9,32]$ and where the blade distance from the tower gradually increases, due to the imposed tilt angle.

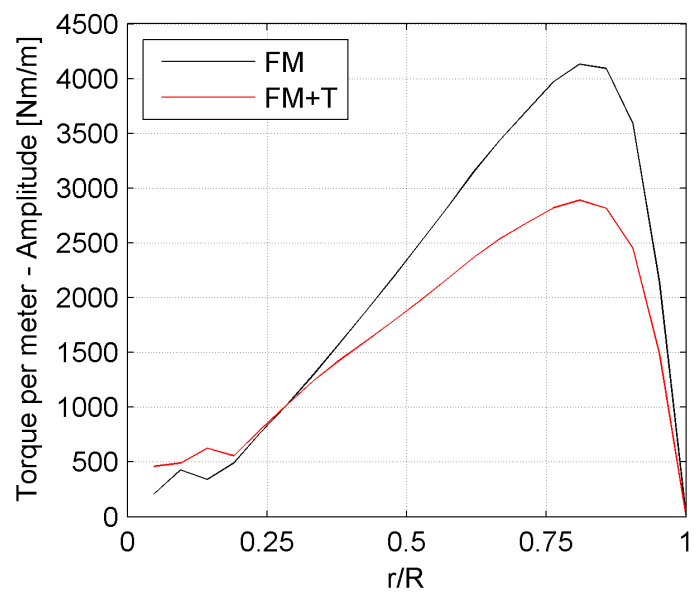

Figure 15. Amplitude of the torque oscillation as a function of the span: FM vs. FM + T.

A similar reasoning applies to the axial force; the tilt angle induces a more intense reduction in its oscillation towards the tip, positively impacting on the fatigue life of the blade (Figure 16). No remarkable change is reported in the distribution of its average value.

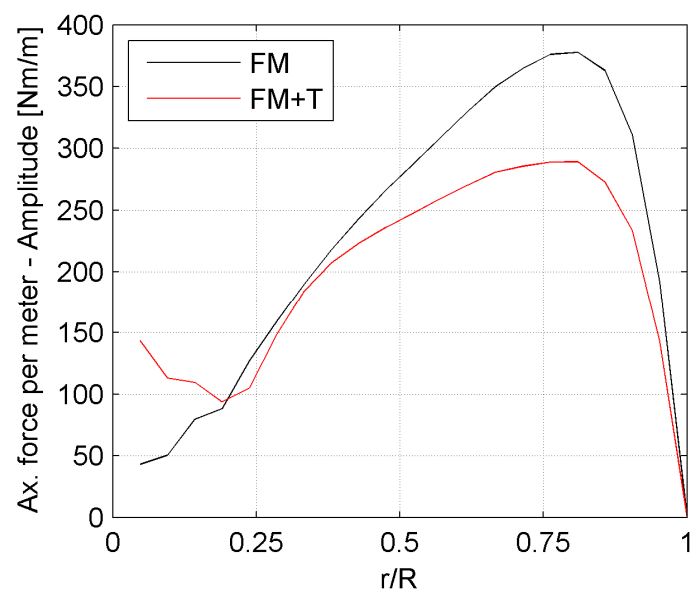

Figure 16. Amplitude of the axial force oscillation as a function of the span: FM vs. FM + T.

\subsection{Yaw Angle}

Figure 17 shows the torque contribution of the single blade in the $\mathrm{FM}+\mathrm{T}$ and $\mathrm{FM}+\mathrm{TY}$ configurations. 


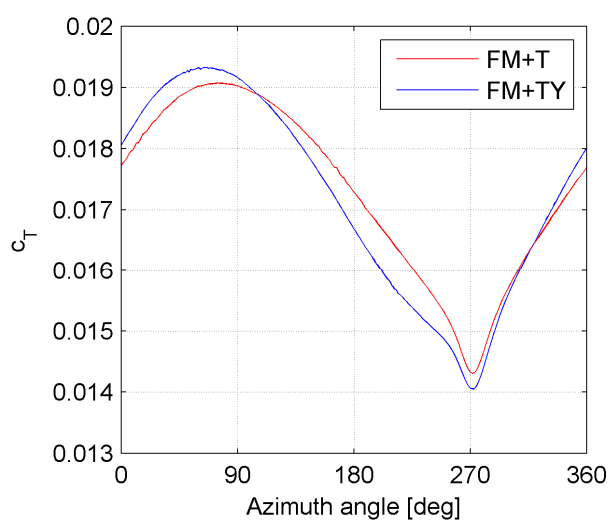

Figure 17. Torque coefficient contribution of each blade as a function of its azimuth angle: FM + T vs. $\mathrm{FM}+\mathrm{TY}$.

In this case, a further shift in phase (anticipation in the positive peak) is reported, but, contrary to the tilted case, an increase in the amplitude of the oscillation is observed. Figure 18 shows the torque contribution at the two previously examined spanwise locations.

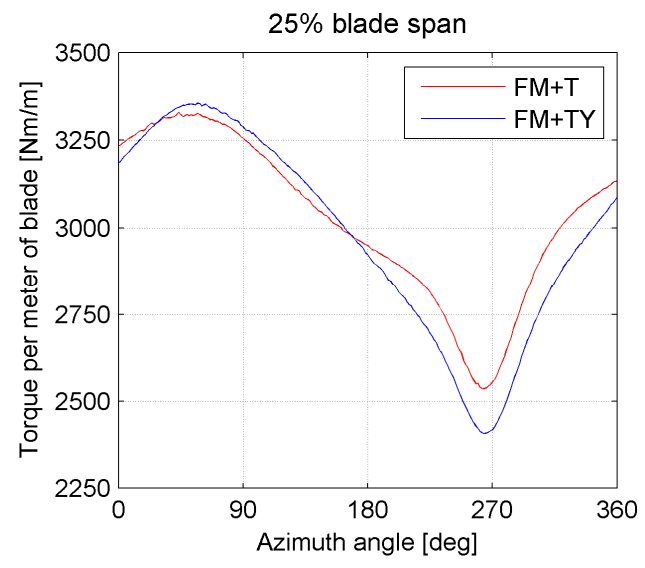

(a)

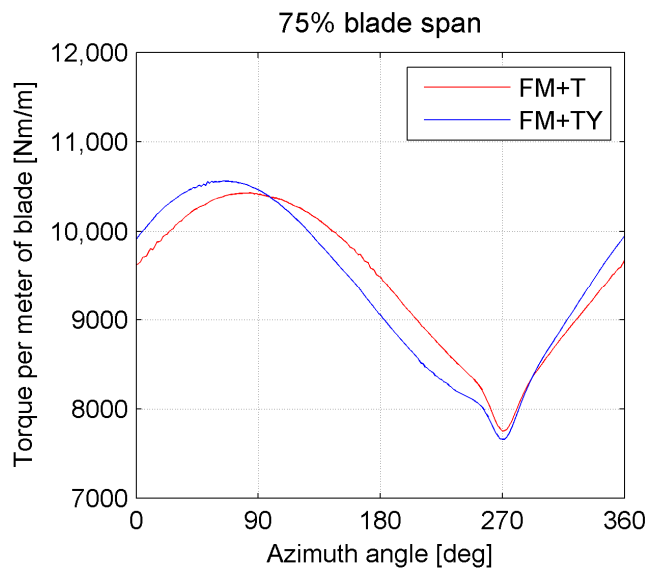

(b)

Figure 18. Torque (per meter of blade) contribution at two different spanwise locations: (a) $25 \%$ and (b) $75 \%$ of the total span. Comparison between the FM + T and FM + TY configurations.

A small phase delay is present at the inboard section examined, in contrast with the phase anticipation monitored in the total torque provided by the blade, as well as in the torque contribution of the outboard section. On the other hand, an increase in the amplitude of the torque oscillation is observed on the whole span of the blade (Figure 19).

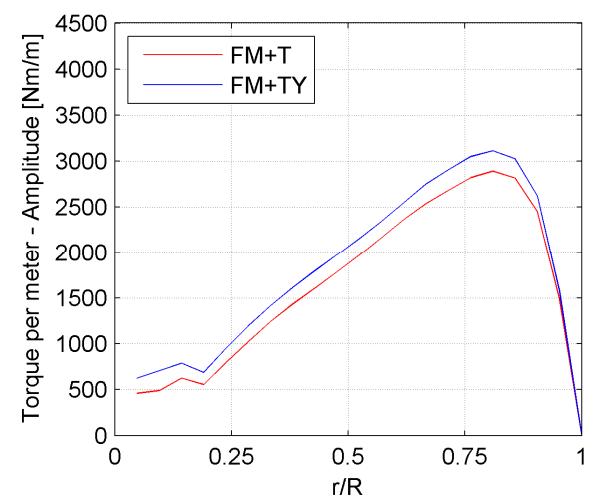

Figure 19. Amplitude of the torque oscillation as a function of the span: FM + T vs. FM + TY. 
The differences in the torque provided by the inboard section can be explained by examining the computed flow angle (Figure 20a), which exhibits a similar delay in the peak value. Differently, the changes in the torque provided by the outboard section do not find an explanation in the computed flow angle (Figure 20b).

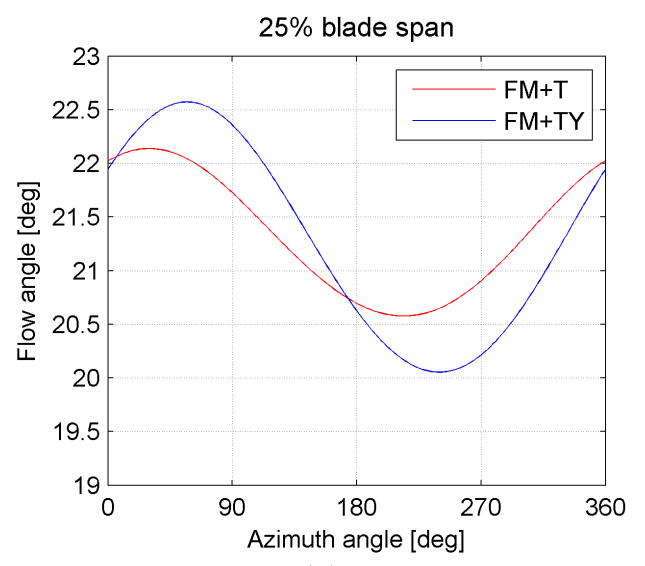

(a)

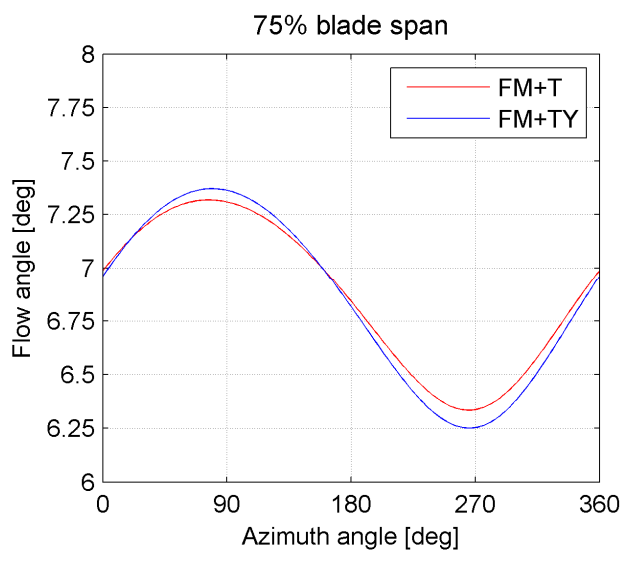

(b)

Figure 20. Computed flow angles at two different spanwise locations: (a) $25 \%$ and (b) $75 \%$ of the total span. Comparison between the FM + T and FM + TY configurations.

Figure 20a shows both a delay in the phase and an increase in the amplitude of oscillation, similarly to what is shown for the torque in Figure 18a. On the other hand, the differences in Figure 20b are very small compared to the differences in Figure $18 \mathrm{~b}$ and the anticipation of the peak observed in the latter is not reported in the flow angle. Similarly to what has been done for the effect of the tilt angle, these differences are related to the different radial flows affecting the outboard part of the blade. Figure 21 shows the computed radial velocity impacting on the pressure side of the blade in both the tilted and tilted-yawed configuration.

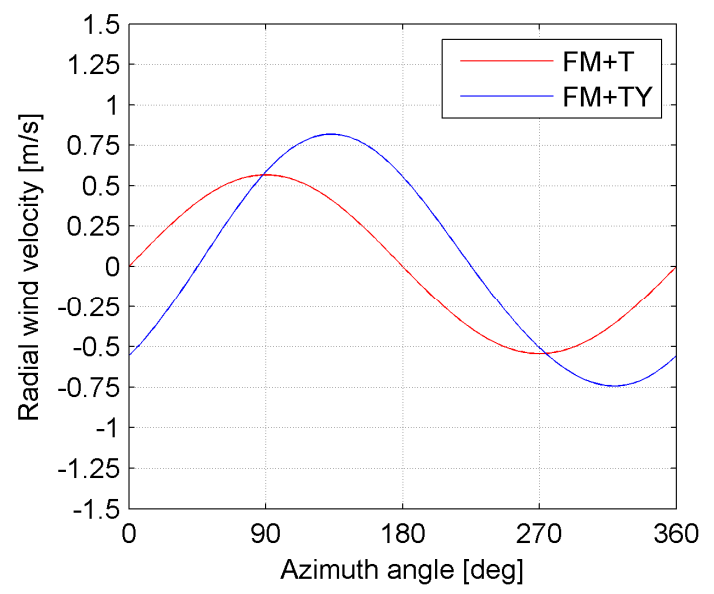

Figure 21. Computed impacting radial wind velocity at 75\% of the blade span (see Figure 4 for the sign convention).

Since a positive velocity denotes a centrifugal flow, which will increase the tip losses and thus reduce the torque production, the difference in radial velocity $\left(-v_{r a d, T Y}\right)-\left(-v_{r a d, T}\right)$ is compared to the difference in torque on the outboard location, as shown in Figure 22. 


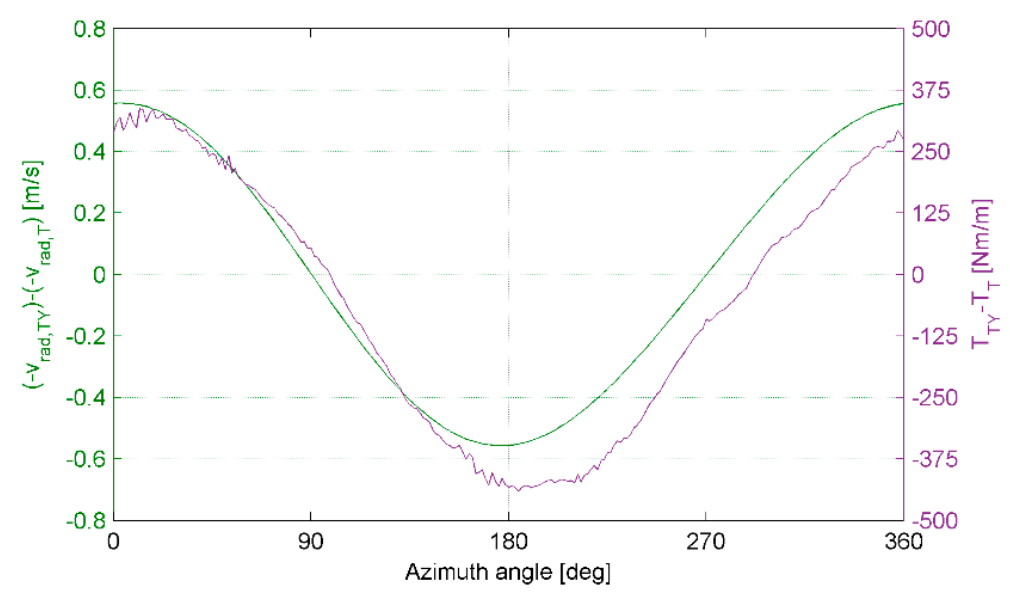

Figure 22. Comparison between the computed negative difference in radial velocity and the difference in torque at $75 \%$ of the blade.

A global phase agreement is observed, supporting the hypothesized relation between the torque production of the outboard section and the incidence of radial flow and tip losses.

Lastly, the imposed yaw positively influences the amplitude of the oscillation of the axial force acting on the blade, as shown in Figure 23, leading to more conservative operating conditions in terms of the lifetime of the blades.

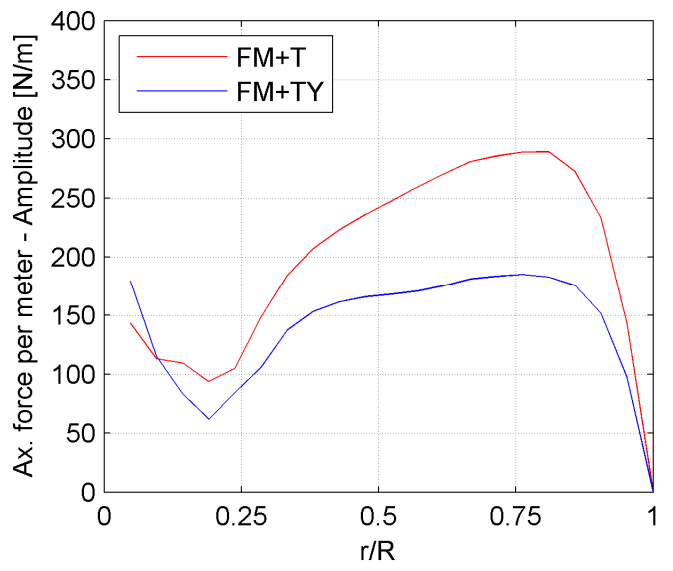

Figure 23. Amplitude of the axial force oscillation as a function of the span: FM + T vs. FM + TY.

\section{Conclusions}

Several computational fluid dynamics simulations of a $100 \mathrm{~m}$ diameter rotor were carried out in order to investigate the effect of the supporting structures and of a rotor tilt and yaw misalignment on the performance and loads of its blades. The machine was immersed in the atmospheric boundary layer in order to account for the wind velocity stratification.

First, the effect of the presence of the supporting structures was analyzed. It leads to a drop in the performance of each blade when it passes in front of the tower. This translates to a fluctuating total torque produced by the turbine and to a bigger amplitude of oscillation of both the torque contribution and the axial force acting on each blade.

Moreover, the effect of tilting the rotor and nacelle of the machine was analyzed. It leads to a less intense fluctuation of both the torque and axial force, leading to a more conservative operating condition for the blades in terms of the fatigue life. On the other hand, it further decreases the average torque produced by the turbine. Different phenomena were observed at the root and the tip of the blade. At the root, the differences in the produced torque are driven by the different distribution of the angle of attack induced by the tilt. On the other hand, these differences are negligible at the tip, where 
the much higher blade speed makes the velocity triangles insensitive to small changes in the direction of the incoming wind speed. Here, the differences in torque are driven by the different radial flow induced by the tilt, which leads to a difference in tip leakage flow. Similar observations were made for the yawed case, where the amplitude of the oscillating torque provided by each blade was increased.

Author Contributions: Conceptualization, G.S., M.P., W.V.P., J.D.; methodology, G.S.; software, G.S.; validation, G.S., J.D.; formal analysis, G.S., J.D.; investigation, G.S.; resources, J.D.; data curation, G.S., M.P.; writing一original draft preparation, G.S.; writing-review and editing, G.S., M.P., W.V.P., J.D.; visualization, G.S.; supervision, J.D., W.V.P.; project administration, W.V.P., J.D.; funding acquisition, W.V.P., J.D.

Funding: This work was supported by the Fonds Wetenschappelijk Onderzoek - Vlaanderen (FWO, grant no. G030414N). The computational resources (Stevin Supercomputer Infrastructure) and services used were provided by the VSC (Flemish Supercomputer Center), funded by Ghent University, the Hercules Foundation and the Flemish Government department EWI.

Acknowledgments: The authors want to thankfully acknowledge Jan Vierendeels for his contribution to this work.

Conflicts of Interest: The authors declare no conflict of interest.

\section{References}

1. Dai, K.; Bergot, A.; Liang, C.; Xiang, W.-N.; Huang, Z. Environmental issues associated with wind energy-A review. Renew. Energy 2015, 75, 911-921. [CrossRef]

2. Artigao, E.; Martin-Martinez, S.; Honrubia-Escribano, A.; Gómez-Lázaro, E. Wind turbine reliability: A comprehensive review towards effective condition monitoring development. Appl. Energy 2018, 228, 1569-1583. [CrossRef]

3. Caduff, M.; Huijbregts, M.A.J.; Althaus, H.J.; Koehler, A.; Hellweg, S. Wind power electricity: The bigger the turbine, the greener the electricity? Environ. Sci. Technol. 2012, 46, 4725-4733. [CrossRef]

4. Calaf, M.; Meneveau, C.; Meyers, J. Large eddy simulation study of fully developed wind-turbine array boundary layers. Phys. Fluids 2010, 22, 015110. [CrossRef]

5. Goit, J.P.; Meyers, J. Optimal control of energy extraction in wind-farm boundary layers. J. Fluid Mech. 2015, 768, 5-50. [CrossRef]

6. Sorensen, J.N. Aerodynamic aspects of wind energy conversion. Annu. Rev. Fluid Mech. 2011, 43, 427-448. [CrossRef]

7. Betz, A. Schraubenpropeller mit geringstem Energieverlust. Mit einem Zusatz von 1. Prandtl. Nachr. Ges. Wiss. Göttingen Math. Phys. Kl. 1919, 1919, 193-217.

8. Glauert, H. Airplane propellers. In Aerodynamic Theory; Durand, W.F., Ed.; Springer: Berlin, Germany, 1935; pp. 169-360.

9. Shen, W.Z.; Mikkelsen, R.; Sorensen, J.N.; Bak, C. Tip loss corrections for wind turbine computations. Wind Energy 2005, 8, 457-475. [CrossRef]

10. Dai, J.C.; Hu, Y.P.; Liu, D.S.; Long, X. Aerodynamic loads calculation and analysis for large scale wind turbine based on combining BEM modified theory with dynamic stall model. Renew. Energy 2011, 36, 1095-1104. [CrossRef]

11. Sorensen, J.N.; Kock, C.W. A model for unsteady rotor aerodynamics. J. Wind Eng. Ind. Aerod. 1995, 58, 259-275. [CrossRef]

12. Shen, X.; Zhu, X.C.; Du, Z.H. Wind turbine aerodynamics and loads control in wind shear flow. Energy 2011, 36, 1424-1434. [CrossRef]

13. Seydel, J.; Aliseda, A. Wind turbine performance in shear flow and in the wake of another turbine through high fidelity numerical simulations with moving mesh technique. Wind Energy 2013, 16, 123-138. [CrossRef]

14. Cai, X.; Gu, R.R.; Pan, P.; Zhu, J. Unsteady aerodynamics simulation of a full-scale horizontal axis wind turbine using CFD methodology. Energ. Convers. Manage. 2016, 112, 146-156. [CrossRef]

15. Fleming, P.; Gebraad, P.M.O.; Lee, S.; van Wingerden, J.-W.; Johnson, K.; Churchfield, M.; Michalakes, J.; Spalart, P.; Moriarty, P. Simulation comparison of wake mitigation control strategies for a two-turbine case. Wind Energy 2014, 18, 2135-2143. [CrossRef] 
16. Annoni, J.; Scholbrock, A.; Churchfield, M.; Fleming, P. Evaluating tilt for wind plants. In Proceedings of the 2017 American Control Conference (ACC), Seattle, WA, USA, 24-26 May 2017; pp. 717-722.

17. Noura, B.; Dobrev, I.; Kerfah, R.; Massouh, F.; Khelladi, S. Investigation of the Rotor Wake of Horizontal Axis Wind Turbine under Yawed Condition. J. Appl. Fluid Mech. 2016, 9, 2695-2705. [CrossRef]

18. Gumuła, S.; Piaskowska-Silarska, M.; Pytel, K.; Noga, H.; Kulinowski, W. Evaluation of the impact of adjusting the angle of the axis of a wind turbine rotor relative to the flow of air stream on operating parameters of a wind turbine model. In Proceedings of the Energy and Fuels Conference, Cracow, Poland, 21-23 September 2016.

19. Song, D.R.; Fan, X.Y.; Yang, J.; Liu, A.; Chen, S.; Joo, Y.H. Power extraction efficiency optimization of horizontal-axis wind turbines through optimizing control parameters of yaw control systems using an intelligent method. Appl. Energy 2018, 224, 267-279. [CrossRef]

20. Fleming, P.A.; Scholbrock, A.K.; Jehu, A.; Davoust, S.; Osler, E.; Wright, A.D.; Clifton, A. Field-test results using a nacelle-mounted lidar for improving wind turbine power capture by reducing yaw misalignment. In Proceedings of the 5th Science of Making Torque from Wind Conference, Copenhagen, Denmark, 18-20 June 2014.

21. Franke, J.; Hellsten, A.; Schlunzen, K.H.; Carissimo, B. The COST 732 Best Practice Guideline for CFD simulation of flows in the urban environment: A summary. Int. J. Environ. Pollut. 2011, 44, 419-427. [CrossRef]

22. Li, Y.; Castro, A.M.; Sinokrot, T.; Prescott, W.; Carrica, P.M. Coupled multi-body dynamics and CFD for wind turbine simulation including explicit wind. Renew. Energy 2015, 76, 338-361. [CrossRef]

23. Sayed, M.; Lutz, T.; Krämer, E. Aerodynamic investigation of flow over a multi-megawatt slender bladed horizontal-axis wind turbine. In Proceedings of the 1st International Conference on Renewable Energies Offshore (RENEW2014), Lisbon, Portugal, 24-26 November 2014.

24. Harte, R.; Van Zijl, G.P.A.G. Structural stability of concrete wind turbines and solar chimney towers exposed to dynamic wind action. J. Wind Eng. 2007, 95, 1079-1096. [CrossRef]

25. Santo, G.; Peeters, M.; Van Paepegem, W.; Degroote, J. Dynamic load and stress analysis of a large horizontal axis wind turbine using full scale fluid-structure interaction simulation. Renew. Energy 2019, 140, 212-226. [CrossRef]

26. Yu, D.O.; Kwon, O.J. Predicting wind turbine blade loads and aeroelastic response using a coupled CFD-CSD method. Renew. Energy 2014, 70, 184-196. [CrossRef]

27. Sayed, M.; Lutz, T.; Krämer, E.; Shayegan, S.; Ghantasala, A.; Wüchner, R.; Bletzinger, K.U. High fidelity CFD-CSD aeroelastic analysis of slender bladed horizontal-axis wind turbine. In Proceedings of the 6th Science of Making Torque from Wind Conference, Munich, Germany, 5-7 October 2016.

28. Richards, P.J.; Hoxey, R.P. Appropriate boundary conditions for computational wind engineering models using the k- $\varepsilon$ turbulence model. J. Wind Eng. Ind. Aerod. 1993, 46-47, 145-153. [CrossRef]

29. Blocken, B.; Stathopoulos, T.; Carmeliet, J. CFD simulation of the atmospheric boundary layer: Wall function problems. Atmos. Environ. 2007, 41, 238-252. [CrossRef]

30. Parente, A.; Gorlé, C.; van Beeck, J.; Benocci, C. A Comprehensive Modelling Approach for the Neutral Atmospheric Boundary Layer: Consistent Inflow Conditions, Wall Function and Turbulence Model. Boundary Layer Meteorol. 2011, 140, 411-428. [CrossRef]

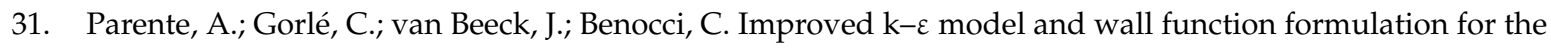
RANS simulation of ABL flows. J. Wind Eng. Ind. Aerod. 2011, 99, 267-278. [CrossRef]

32. Hau, E. Wind Turbines: Fundamentals, Technologies, Application, Economics, 2nd ed.; Springer: Berlin, Germany, 2006.

33. Bazilevs, Y.; Hsu, M.C.; Akkerman, I.; Wright, S.; Takizawa, K.; Henicke, B.; Spielman, T.; Tezduyar, T.E. 3D simulation of wind turbine rotors at full scale. Part I: Geometry modeling and Aerodynamics. Int. J. Numer. Methods Fluids 2010, 65, 207-245. [CrossRef]

34. Bazilevs, Y.; Hsu, M.C.; Kiendl, J.; Wuchner, R.; Bletzinger, K.U. 3D simulation of wind turbine rotors at full scale. Part II: Fluid-structure interaction modeling with composite blades. Int. J. Numer. Methods Fluids 2010, 65, 236-253. [CrossRef] 
35. Van Paepegem, W.; Degrieck, J. A New Coupled Approach of Residual Stiffness and Strength for Fatigue of Fiber-Reinforced Composites. Int. J. Fatigue 2002, 24, 747-762. [CrossRef]

36. Bazilevs, Y.; Korobenko, A.; Deng, X.; Yan, J. Fluid-structure interaction modeling for fatigue-damage prediction in full-scale wind-turbine blades. J. Appl. Mech. 2016, 83, 061010. [CrossRef]

(C) 2019 by the authors. Licensee MDPI, Basel, Switzerland. This article is an open access article distributed under the terms and conditions of the Creative Commons Attribution (CC BY) license (http://creativecommons.org/licenses/by/4.0/). 